\title{
Kinetic parameters from linear plot vis-á-vis condition for validity of various quasi steady state approximations
}

\begin{abstract}
Background: Many researchers often adopt linear transformations of Michaelis-Menten (MM) equation for the determination of kinetic parameters. The most popular and most criticized is Lineweaver Burk (LWB) plot. Direct (or alternative direct) linear plot (DLP or ADLP) is another approach. It is not certain whether or not MM constant in particular is valid if consideration is given to the condition of validity of various quasi steady state approximations (QSSA).

Objectives: The objectives of this research are to

i. Determine kinetic parameters by DLM, ADLM and LWB methods,

ii. Investigate the effect of high and low substrate concentration regime,

iii. Investigate the effect of lower and much higher concentration of enzyme

iv. Examine the mathematical formalism that characterize relevant QSSA so as to determine the consistency in the units of parameters and

v. Examine if the concentration of the substrate and enzyme satisfy the condition for validity of various QSSA.
\end{abstract}

Method: The theoretical perspective includes mathematical approach to system biology typified by MM equation and various equation of validation. The experiment entails Bernfeld method of enzyme assay for the generation of data. (Modified or alternative) direct linear plots were carried out using Microsoft Excel.

Results: Instead of MM constant $K$, enzyme - substrate complex dissociation constant, $K_{s}$ was obtained with different substrate concentration ranges and different enzyme concentration viz: 0.769 and $1.92 \mu \mathrm{mol} / \mathrm{L}$. The maximum velocities of hydrolysis reported may be lower than what the value could be if saturating concentration of the substrate was used.

Conclusion: Different ranges of substrate concentration $\left[S_{\mathrm{T}}\right]$ and different higher concentration of the enzyme may not yield the same kinetic parameters. The condition of validity of QSSA is more verifiable if mole concept is applied. All kinetic parameters satisfy the condition of validity of rQSSA, and, consequently, $K_{s}$ instead of $K_{m}$, was yielded.

Keywords: kinetic parameters, standard quasi steady state approximation, total quasi steady state approximation, reverse quasi steady state approximation, reactant stationary assumption, direct linear plot, alternative direct linear plot, lineweaver burk plot, aspergillus oryzea alpha amylase
Volume 9 Issue 2 - 2018

\section{Ikechukwu lloh Udema}

Department of Biochemistry and Chemistry, Research Division of Ude International Concepts Limited, Nigeria

Correspondence: Ikechukwu lloh Udema, Research Division of Ude International Concepts Limited (RC 862217) B.B.Agbor, Delta State, Nigeria, Tel +2340 80374769 70, Email udema_ikechukwu99@yahoo.com

Received: February 25, 2018 | Published: March 22, 2018
Abbreviations: MM, Michaelis - Menten LWB, Lineweaver burk plot; DLP, direct linear plot; ADLP, alternative direct linear plot; sQSSA, standard Quasi Steady State Approximation; rQSSA, reverse Quasi Steady State Approximation; tQSSA, total Quasi Steady State Approximation; RSA, reactant stationary assumption

\section{Introduction}

For many years, scientist with interest in enzymology determined molecular mechanism and estimated kinetic constants of enzymecatalyzed reactions by exploring what Grima et al. ${ }^{1}$ cited as initial rates, progress curve, transient kinetic, and relaxation experiments. In the $20^{\text {th }}$ and $21^{\text {st }}$ century, there are lot of research papers covering the determination of kinetic parameters of enzymes, often described as the characterization of enzymes from different sources. ${ }^{2-5}$ Thermodynamic characterization of enzyme which is dependent on predetermined kinetic parameters is also of great interest to enzymologist. ${ }^{6}$ Most of the experiments are on single enzyme, single substrate reaction, being the original work of Henri as cited in most research papers. ${ }^{1,7}$ Henri based his ideas on the scheme (Eq. (1)) as follows.

$$
\begin{gathered}
k_{1} \quad k_{2} \\
E+S \rightleftharpoons C \rightarrow P+E \\
k_{-1}
\end{gathered}
$$

What seems to be lacking in the scheme is the possibility of the presence of a fragment if polysaccharide is the substrate. Besides when a known volume of the enzyme is added to the test tube containing the substrate, a fraction of the total enzyme concentration binds a fraction of the substrate at the active site. The scheme gives the impression that the whole of free enzyme, $E$ binds with the whole of $S$ to form a complex, $C$. It may therefore, be appropriate to state that $S$ and $E$ are part of the total substrate $\left[S_{\mathrm{T}}\right]$ and enzyme $\left[E_{\mathrm{T}}\right]$ concentration 
that formed a complex, $C$ which after amylolytic action, breaking and making of bonds, breaks up into products, detectable part or the reducing sugar and undetectable part, the fragment if a polysaccharide is the substrate and the free enzyme, $E$.

Despite the known origin of scheme 1, the scheme according to Grima et al. ${ }^{1}$ is credited to Michaelis-Menten et al, ${ }^{8} 1913$ paper because of their research on the rate of enzyme catalyzed reaction. The most important issue here is initial rate when the substrate concentration is much $<\mathrm{MM}$ constant $\left(K_{\mathrm{m}}\right)$ when the duration of assay must not permit substrate depletion such that the rate of product formation must be at least directly proportional to substrate concentration $\left[S_{\mathrm{T}}\right]$ so as to achieve coefficient of determination $\left(R^{2}\right) \geq 0.999$. This is to say that at every $\left[S_{\mathrm{T}}\right]$ below $K_{\mathrm{m}}$ the proportionality constant must be consistent. It may not be only $\left[S_{\mathrm{T}}\right]$ below $K_{\mathrm{m}}$, the duration of assay is also very crucial; shorter time regime is much preferable.

There has also been issue regarding inappropriate linearization of MM equation for the determination of kinetic parameters. The most popular and widely used is Lineweaver et al. ${ }^{9}$ approach that has been criticized for yielding grossly inaccurate kinetic parameters. ${ }^{10,11}$ Because of substantial errors associated with linear transformation methods cited in Diaci, ${ }^{12}$ direct linear methods (DLP) ${ }^{12}$ and alternative DLP (ADLM $)^{13}$ for the determination of kinetic parameters seem to be gaining very wide acceptance. The three popular linear transformations of the Michaelis-Menten equation cited in Biaci ${ }^{12}$ are, namely the double reciprocal plot (Lineweaver-Burk), the $v$ against $v / s$ plot, often called the Eadie-Hofstee plot, the s/v against s plot (HanesWoolf), which are shown respectively below.

$$
\begin{aligned}
& \frac{1}{v}=\frac{K_{\mathrm{m}}}{v_{\max }\left[S_{\mathrm{T}}\right]}+\frac{1}{v_{\max }} \\
& v=v_{\max }-\frac{K_{\mathrm{m}} v}{\left[S_{\mathrm{T}}\right]} \\
& \underline{[S]}=\frac{\left[S_{\mathrm{T}}\right]}{v}+\frac{K_{\mathrm{m}}}{v_{\text {max }}}
\end{aligned}
$$

Where $v$ and $v_{\max }$ are the velocity of product formation and maximum velocity of product formation respectively. Equations (2) in particular, (3) and (4) need not further interpretation for those with average or minimal appreciation of basic algebra. There has also been very serious statistical consideration for the estimation of enzyme kinetic parameters, considerations that have favored nonparametric methods. ${ }^{14}$ Nonetheless there are issues against direct linear method as to imply that it is far from perfection. Precise point of interception of two or more lines may not be clearly defined if such intersection is acute. ${ }^{15}$

There are also recent developments that set conditions for the validity of $\mathrm{MM}$ formalism and consequently kinetic parameters derivable from it. These are anchored on various kinds of approximations or assumptions such as standard quasi steady state approximation (sQSSA), ${ }^{16}$ reverse QSSA (rQSSA), ${ }^{17,18}$ total QSSA (tQSSA) ${ }^{18,19}$ and recently reactant stationary assumption (RSA). ${ }^{7}$ Guided nutritional regime and therapeutic administration of drug/formulation requires accurate information about the condition of validity of the kinetic parameters of the enzyme that may be functionally connected to the food ingredients and drugs. The objectives of this research are to i. Determine kinetic parameters by DLM, ADLM and Lineweaver Burk method,

ii. Investigate the effect of high and low substrate concentration regime,

iii. Investigate the effect of lower and much higher concentration of enzyme,

iv. Examine the mathematical formalism that characterize relevant QSSA so as to determine the consistency in the units of parameters, and

v. Examine if the substrate concentration regime as well as enzyme concentration regime from which kinetic parameters are generated following assay satisfy the condition for validity of various QSSA.

\section{Theory}

As a follow-up to the concern expressed earlier in the introductory section, this section begins with arithmetical and stoichiometric analysis as to why $E+S \rightarrow C$ may just be a combination of a part of total substrate, $S_{\mathrm{T}}$ (i.e. $S$ ) and part of total enzyme, $E_{\mathrm{T}}$ (i.e. $E$ ) to form enzyme-substrate complex, $C$, all with a view to be in line with mass conservation principle. Thus the mathematical protocol developed by Briggs et al. ${ }^{16}$ has been considered as a standard approach to the derivation of the MM equation on the basis of Henri's scheme using the steady state assumption otherwise called SQSSA as to imply that,

$$
v_{\mathrm{c}}\left(\text { i.e. } \frac{\mathrm{d} c}{\mathrm{~d} t}\right) \approx 0
$$

Since the derivation of MM equation is usually in many related papers, the entire procedure for the derivation is cut short starting with the following:

$$
\begin{gathered}
E_{\mathrm{T}}=E+C \\
{[C]=\frac{\left[E_{\mathrm{T}}\right][S]}{K_{\mathrm{m}}+[S]}}
\end{gathered}
$$

Where $K_{\mathrm{m}}$ is the MM constant expressed as:

$$
K_{\mathrm{m}}=\frac{k_{-1}+k_{2}}{k_{1}}
$$

On the basis of enzyme mass conservation law,

$$
[C] M_{2} \leq\left[E_{\mathrm{T}}\right] M_{2}
$$

Where $M_{2}$ is the molar mass of the enzyme and with appropriate experimental condition, ${ }^{7}$

$$
\frac{\left[E_{\mathrm{T}}\right]}{\left[S_{\mathrm{T}}\right]} \ll 1
$$

This condition may stand so long as the unit of $\left[\mathbf{S}_{\mathrm{T}}\right]$ is mole per liter so as to be in line with stoichiometry.

The approximation ${ }^{7}$ during the initial transient of the reaction is given as follows: $[S] \approx\left[S_{\mathrm{T}}\right]$. But $S$ appears in scheme 1 (Eq. (1)) and thus seem to suggest that the entire $S$ in the scheme formed complex with the enzyme, $E$. That is to imply that $[S]$ formed complex with $[E]$ which was released after the formation of product. Therefore, it is either different symbols are used to represent the concentration of 
the enzyme that combined with same concentration of the substrate on 1:1 mole ratio basis that satisfies stoichiometric requirement or $E$ and $S$, ab initio, are respectively seen to be the fraction of the total enzyme and substrate that form the enzyme-substrate complex $C$ or $E S$ at the initial transient or infinitesimal part of the chosen duration of assay for one active site - enzyme - one substrate system. It seems the true position may be that at the initial transient when the remaining concentration of the substrate $[S]\left(\right.$ or $\left[S_{\mathrm{T}}\right] / \exp (k t)$ is $\approx$ $\left[S_{\mathrm{T}}\right]$ goes to confirm that only a fraction of $\left[S_{\mathrm{T}}\right]$ may have combined with the enzyme, a fraction of which detects the fraction of substrate that binds to it. Thus $S$ as used in most journals should not represent part of the total substrate that formed complex with the enzyme and the remaining substrate whose magnitude may be $\approx\left[S_{\mathrm{T}}\right]$ at the initial transient. To justify this position the arithmetical analysis as follows is relevant. If $\delta$ is taken as the infinitesimal amount of the enzyme that binds the substrate, on one 1mole:1mole basis for single enzyme molecule (one active site)-single substrate molecule system, $\delta$ of the substrate also binds at the active sites to form the enzyme-substrate complex. By taking the symbols $\left[E_{\mathrm{T}(\mathrm{mol})}\right],\left[S_{\mathrm{T}(\mathrm{mol})}\right]$ respectively, as molar concentrations of the total enzyme and substrate, and $C_{\mathrm{MC}}$ as mass concentration of the enzyme-substrate complex, and $M_{2}$ and $M_{3}$ respectively as the molar mass of the enzyme and substrate, the initial mass conservation equation can be written as:

$\left(\left[E_{\mathrm{T}(\mathrm{mol})}\right]\right) M_{2}+\left(\left[S_{\mathrm{T}(\mathrm{mol})}\right]\right) M_{3}+C_{\mathrm{MC}}=\left[E_{\mathrm{T}(\mathrm{g})}\right]+\left[S_{T(\mathrm{~g})}\right](11)$

Meanwhile, when the complex breaks up releasing the free enzyme whose molar concentration is $\delta$, the molar concentration of the reducing sugar is $=\varphi \delta$ where $\varphi$ is one if one molecule of detectable product is formed one at a time as applicable to oligosaccharides and polysaccharides in which a polysaccharide fragment is left ${ }^{20}$ and 2 if the substrate is a disaccharide. Equation (11) is relevant to the moment the complex is formed. Thus, $\left[E_{\mathrm{T}(\mathrm{mol})}\right] M_{2}=\left[E_{\mathrm{T}(\mathrm{g})}\right]$ and consequently, expansion of Eq. (11) gives,

$$
C_{\mathrm{MC}}=\delta\left(M_{2}+M_{3}\right)
$$

Equation (12) is very basic in nature accounting for the fact that the complex is heterogeneous, hence the sum of different molar masses multiplied by the molar concentration of the enzyme or substrate participating in complex formation. But the situation is quite different when $0 \ll \mathrm{t} \ll \infty$. This implies that, when $0 \ll t \ll \infty$, the mass concentration of the spectrophotometrically detected product (if a polysaccharide is a substrate) can be subtracted from $\left[S_{\mathrm{T}(\mathrm{g})}\right]$ to give:

$$
\left[S_{\mathrm{T}(\mathrm{g})}\right]-\left[P_{(\mathrm{g})}\right](t)=\left[\hat{S}_{(\mathrm{g})}\right](t)=\left[C_{(\mathrm{g})}^{\mathrm{S}}\right](t)+\left[S_{(\mathrm{g})}^{\mathrm{R}}\right](t)
$$

Equation (13) is in line with substrate mass conservation principle (where it has been made abundantly clear that $\mathrm{C}$ as in most journals cannot jointly stand for the concentration of the substrate and enzyme forming complex at the same time $)^{20}$ in which the unit of every chemical species is $\mathrm{g} / \mathrm{L}$. The superscript $\mathrm{S}$ and $\mathrm{R}$ are substrate and remainder describing $\left[C_{(\mathrm{g})}^{S}\right](t)$ and $\left[S_{(\mathrm{g})}^{\mathrm{R}}\right](t)$ respectively as mass concentration of the substrate that formed complex and the remaining substrate (as sum of unhydrolyzed polysaccharide and fragment of polysaccharide if polysaccharide is the substrate). Just about the time the assay is to be terminated at time, $t$ some of the molecules of enzyme are engaging the substrate in complex formation, otherwise the complex from which the product is released cannot exist at the same time as the product; the complex ceases to exist as soon as the product is released.

With regard to sQSSA, Schnell ${ }^{7}$ derived an equation of validation. The equation is:

$$
\frac{\left[E_{\mathrm{T}}\right]}{K_{\mathrm{m}}+\left[S_{\mathrm{T}}\right]} \ll\left(1+\frac{K_{S}}{K}\right)\left(1+\frac{\left[S_{\mathrm{T}}\right]}{K_{\mathrm{m}}}\right)
$$

Where $K_{\mathrm{S}}=k_{-1} / k_{1}$ (the equilibrium dissociation constant of $C$ ) and $K=k_{2} / k_{1}$ (the Van Slyke-Cullen constant ${ }^{21}$ ). Equation presents two different constant $\left(K_{\mathrm{S}}\right.$ and $\left.K\right)$ that have to be separately determined. Equation containing only rate constant is derived by substituting the equation of $K_{\mathrm{S}}$ and $K$ into Eq. (14) to give:

$$
\text { «(1+ } \left.\frac{k_{-1}}{k_{2}}\right)\left(1+\frac{\left[S_{\mathrm{T}}\right]}{K_{\mathrm{m}}}\right)
$$

The concern regarding Eq. (14 and 15) is that $\frac{\left[E_{\mathrm{T}}\right]}{K_{\mathrm{m}}+\left[S_{\mathrm{T}}\right]}$ lacks consistency in its unit because the concentration of enzyme and the substrate $/ K_{\mathrm{m}}$ are for different chemical species with different molar masses. It is possible that the ratio of $\left[E_{\mathrm{T}(\mathrm{g})}\right]:\left(K_{\mathrm{m}}+\left[S_{\mathrm{T}(\mathrm{g})}\right]\right)$ is $<1$ if $K_{\mathrm{m}}$ is left with unit as $\mathrm{g} / \mathrm{L}$ because the mass concentration of $E$ is most often in cg, $\mathrm{mg}$ or $\mu \mathrm{g}$ per liter. The ratio $\left[S_{\mathrm{T}}\right]: K_{\mathrm{m}}$ presents no problem because the same chemical species are involved. Therefore, it is imperative to insist that the molar mass of the substrate must be known as long as the concentration of the total enzyme is in mol/L. Therefore, Eq. (14) and Eq. (15) can be restated with new symbols as follows:

$$
\begin{aligned}
& \frac{\left[E_{\mathrm{T}(\mathrm{mol})}\right]}{K_{\mathrm{m}}+\left[S_{\mathrm{T}(\mathrm{mol})}\right]} \ll\left(1+\frac{K_{S}}{K}\right)\left(1+\frac{\left[S_{\mathrm{T}(\mathrm{mol})}\right]}{K_{\mathrm{m}}}\right) \\
& \ll\left(1+\frac{k_{-1}}{k_{2}}\right)\left(1+\frac{\left[S_{\mathrm{T}(\mathrm{mol})}\right]}{K_{\mathrm{m}}}\right)
\end{aligned}
$$

Here, in Eq. (16) and Eq. (17) MM constant is retained in its traditional symbol but with $\mathrm{mol} / \mathrm{L}$ as its unit. Unit of a variable, constant etc is extremely vital to valid assessment of any data, kinetic parameters for instance.

While recognizing Schnell et al. ${ }^{18}$ disagreement with the proposition that at high enzyme concentrations, the correct physical assumption is $\frac{\mathrm{d} C}{\mathrm{~d} t} \approx 0$ as against $\frac{\mathrm{d} S}{\mathrm{~d} t} \approx 0$ in line with rQSSA, Tzafriri ${ }^{19}$ noted that Borghans et al..$^{22}$ extended the validity of the SQSSA by employing a change of variable from $S$ to the total substrate concentration, $S+C=S_{\mathrm{T}}-P \quad$ (this is restated respectively as $\left[S_{(\mathrm{g})}^{\mathrm{R}}\right](t)$ and $\left[\hat{S}_{(\mathrm{g})}\right](t)=\left[C_{(\mathrm{g})}^{S}\right](t)+\left[S_{(\mathrm{g})}^{\mathrm{R}}\right](t)=\left[S_{\mathrm{T}(\mathrm{g})}\right]-\left[P_{(\mathrm{g})}\right](t) . \quad$ This is with regard to what Tzafriri $^{19}$ referred to as tQSSA. Furthermore, uniform condition for the validity of tQSSA has been proposed and derived and simplified in a way that is not clear ${ }^{19}$ though derivation without further simplification is straight forward as follows: In the 
first place, the condition for uniform validity is given as ${ }^{19}$

$$
\begin{aligned}
& \text { Where, } \\
& t_{\mathrm{c}}=\frac{\left(\frac{k_{2} C_{-}\left(S_{\mathrm{T}}\right)}{\left[\mathrm{S}_{\mathrm{T}(\mathrm{g})}\right]} t_{\mathrm{c}} \ll 1\right.}{k_{1} \sqrt{\left(\left[E_{\mathrm{T}(\mathrm{mol})}\right]+K_{m}+\left[S_{\mathrm{T}(\mathrm{mol})}\right]\right)^{2}-4\left[E_{\mathrm{T}(\mathrm{mol})}\right]\left[S_{\mathrm{T}(\mathrm{mol})}\right]}}
\end{aligned}
$$

$2 C_{-}\left(S_{\mathrm{T}}\right)=\left(\left[E_{\mathrm{T}(\mathrm{mol})}\right]+K_{m}+\left[S_{\mathrm{T}(\mathrm{mol})}\right]\right)-\sqrt{\left(\left[E_{\mathrm{T}(\mathrm{mol})}\right]+K_{m}+\left[S_{\mathrm{T}(\mathrm{mol})}\right]\right)^{2}-4\left[E_{\mathrm{T}(\mathrm{mol})}\right]\left[S_{\mathrm{T}(\mathrm{mol})}\right]}$

Substitution of Eq (18b) and Eq. (18c) into Eq. (18a) gives after rearrangement the following:

$\varepsilon=\frac{k_{2}}{2 k_{1}\left[S_{\mathrm{T}(\mathrm{mol})}\right]}\left\{\frac{\left(\left[E_{\mathrm{T}(\mathrm{mol})}\right]+K_{m}+\left[S_{\mathrm{T}(\mathrm{mol})}\right]\right)}{\sqrt{\left(\left[E_{\mathrm{T}(\mathrm{mol})}\right]+K_{m}+\left[S_{\mathrm{T}(\mathrm{mol})}\right]\right)^{2}-4\left[E_{\mathrm{T}(\mathrm{mol})}\right]\left[S_{\mathrm{T}(\mathrm{mol})}\right]}}-1\right\} \ll 1$

But, $k_{1}=\frac{k_{1}+k_{2}}{K_{\mathrm{m}}}$. Substituting this into Eq. (19a) gives:

$\varepsilon=\frac{k_{2} K_{m}}{2\left[S_{T(\mathrm{~mol})}\right]\left(k_{-1}+k_{2}\right)}\left\{\frac{\left(\left[E_{T(\mathrm{~mol})}\right]+K_{m}+\left[S_{T(\mathrm{~mol})}\right]\right.}{\sqrt{\left(\left[E_{T(\mathrm{~mol})}\right]+K_{m}+\left[S_{T(\mathrm{~mol})}\right]\right)^{2}-4\left[E_{T(\mathrm{~mol})}\right]}\left[S_{T(\mathrm{~mol})}\right]}-1\right\} \ll 1$

It is obvious that Eq. (19a) and Eq. (19b) satisfy the concern for consistency in the unit of all parameters if the unit of $k_{1}$ is $\mathrm{L} / \mathrm{mol}$. min and outside the curled bracket $K_{\mathrm{m}}$ as nominator and $\mathrm{S}_{\mathrm{T}(\mathrm{mol})}$ as denominator guarantees dimensionless $\varepsilon$ so long as the unit of $K_{\mathrm{m}}$ is $\mathrm{mol} / \mathrm{L}$; it is immaterial if both are mass concentration because as stated earlier they $\left(K_{\mathrm{m}}\right.$ and $\left.\left[\mathrm{S}_{\mathrm{T}}\right]\right)$ serve the same chemical species. In this regard the denominator and nominator in the curled bracket cannot be an exception. There is no doubt that the inequality (Eq.

$(19 b))$ is a reality because $\frac{k_{2}}{2\left(k_{1}+k_{2}\right)}$ and if, as expected $\mathrm{K}_{\mathrm{m}}$ is $<$ $\left[S_{\mathrm{T}(\mathrm{mol})}\right], \sqrt{\left(\left[E_{\mathrm{T}(\mathrm{mol})}\right]+K_{m}+\left[S_{\mathrm{T}(\mathrm{mol})}\right]\right)^{2}-4\left[E_{\mathrm{T}(\mathrm{mol})}\right]\left[S_{\mathrm{T}(\mathrm{mol})}\right]}$,

is infinitesimally $<\left(\left[E_{\mathrm{T}(\mathrm{mol})}\right]+K_{m}+\left[S_{\mathrm{T}(\mathrm{mol})}\right]\right)$, the solution to the problem in the curled bracket may be $« 1$. This is the tQSSA condition derived by changing variable from free substrate concentration to total substrate concentration $\left[\hat{S}_{(\mathrm{g})}\right](t)$ which may be confused with the total substrate concentration ${ }^{19}\left[\mathrm{~S}_{\mathrm{T}(\mathrm{g})}\right]$ when $t=0$. However, Schnell et al. ${ }^{18}$ objected QSSA when $\mathrm{d}[C] / \mathrm{d} t \approx 0$ as against $\mathrm{d}[S] / \mathrm{d} t \approx 0$. Instead the authors came up with two ways to derive the condition of rQSSA. Such are the selection of appropriate time-scales and assurance that $\Delta$ $[E] \approx 0$ at the initial transient to be the basis for deriving the necessary conditions for the validity of quasi-steady-state assumptions. The first condition is:

$$
\frac{k_{2}}{k_{1}\left[E_{\mathrm{T}(\mathrm{mol})}\right]} \ll 1
$$

With the definition of $\mathrm{k}_{1}$ and its substitution into Eq. (20a) gives:

$$
\frac{k_{2} K_{\mathrm{m}}}{\left(k_{-1}+k_{2}\right)\left[E_{\mathrm{T}(\mathrm{mol})}\right]} \ll 1
$$

According to Schnell et al. ${ }^{18}$, if $k_{-1} \ll k_{2}$ i.e. if there is prima facie evidence,

$$
\frac{K_{\mathrm{m}}}{\left[E_{\mathrm{T}(\mathrm{mol})}\right]} \ll 1
$$

Thus to be valid ab initio, $k_{1}\left[E_{\mathrm{T}(\mathrm{mol})}\right]$ in Eq. (20a) must be like frequency or pseudo first order rate constant (per unit time), $K_{\mathrm{m}}$ must be in $\mathrm{mol} / \mathrm{L}$ as to be consistent with the unit of the enzyme, $\mathrm{E}$ in Eq. (20b) and Eq. (21). Equation (20a, 20b, and 21) need to be examined with caution because even if $k_{-1} \ll k_{2}, \frac{k_{2}}{k_{1}+k_{2}}$ will always be $<1$ but there is no guarantee that $\frac{K_{m}}{\left[E_{\mathrm{T}(\mathrm{mol})}\right]}$ may be $<1$; if the molar mass of the substrate is say $1000 \mathrm{~g} / \mathrm{L}$ the molar concentration of $K_{\mathrm{m}}$ may be > $\left[E_{\mathrm{T}(\mathrm{mol})}\right]$; it is unusual and unlikely that the molar concentration of $\left[E_{\mathrm{T}(\mathrm{mol})}\right]=1 \mathrm{~mol} / \mathrm{L}$ but it is not immeasurable if desired. The case of disaccharide is an example. However, if the substrate is a large polysaccharide with degree of polymerization $\geq 2 \exp (6)$, the fraction $K_{m}$ $\left[E_{\mathrm{T}(\mathrm{mol})}\right]$

This is the strong reason why mole concept must play prominent role in the determination. of validity of kinetic parameter using validation model.

The last but not necessarily the least is the condition for the validity of the RSA. ${ }^{7}$ The condition is not different from that proposed in literature ${ }^{17,23}$ and described as a more general condition for the sQSSA to be valid..$^{18}$ The condition is:

$$
\frac{\left[E_{\mathrm{T}(\mathrm{mol})}\right]}{K_{\mathrm{m}}+\left[S_{\mathrm{T}(\mathrm{mol})}\right]} \ll 1
$$

However, this must be on the basis of mass-mass ratio otherwise if $\left[E_{\mathrm{T}(\mathrm{mol})}\right]$ is high and the molar mass of the substrate is very large as applicable to polysaccharides (native potato starch has molar mass = $8.8 \exp (7) \mathrm{g} / \mathrm{mol},{ }^{24}$ Eq. (22) may not be valid on mole-mole ratio basis which should be the most appropriate way to examine the validity of kinetic parameters. It is not probable that a mass concentration of gelatinized starch $=600 \mathrm{~g} / \mathrm{L}$ can be prepared in usual laboratory research. It has been reported that high concentration of gelatinized starch retard the velocity of hydrolysis due to hydrodynamic constraint related to extreme viscosity. ${ }^{25}$ However, Eq. (22) may be valid so long as, $\left[E_{\mathrm{T}(\mathrm{mol})}\right] M_{2}$ the mass concentration is within the microgram milligram scale. But it should be noted that at very low concentration of enzyme, the enzyme losses its activity. ${ }^{26}$

\section{Materials and methods}

\section{Materials}

Aspergillus oryzea alpha amylase (EC 3:2:1:1) and potato starch were purchased from Sigma - Aldrich, USA. Hydrochloric acid, sodium hydroxide, and sodium chloride, were purchased from BDH 
Chemical Ltd, Poole England. Tris, 3, 5-dinitrosalicylic acid, maltose, and sodium potassium tartrate tetrahydrate were purchased from Kem light laboratories Mumbai India, while potassium iodide was purchased from Merck Germany. Distilled water was purchased from local market.

\section{Equipment}

Electronic weighing machine was purchased from Wenser Weighing Scale Limited and 721/722 visible spectrophotometer was purchased from Spectrum Instruments China. PH meter was purchased from Hanna Instruments, Italy. Water bath was purchased from Hospibrand, USA.

\section{Method}

Twenty grams of potato starch was mixed in $100 \mathrm{~mL}$ of distilled water and boiled at $100^{\circ} \mathrm{C}$ for 3 minutes, cooled to room temperature, and decrease in volume was corrected by topping the volume with distilled water to $100 \mathrm{~mL}$ to give $20 \mathrm{~g} / \mathrm{L}$ as stock. Dilution of the stock was made to give different concentration ranges viz: from $0.5-4 \mathrm{~g} / \mathrm{L}$, 2-4 g/L, and 10-20 g/L. Stock solution of the enzyme was prepared by dissolving $0.01 \mathrm{~g}$ of the enzyme in a buffer tablet solution $(\mathrm{pH}=7)$ to which is added $15 \mathrm{~mL} \mathrm{NaCl}(\mathrm{aq})(0.9 \mathrm{~g} / 100 \mathrm{~mL})$ and $15 \mathrm{~mL} \mathrm{CaCl}$ $(5 \mathrm{mmol} / \mathrm{L})$ to final volume of $100 \mathrm{~mL}$. Different concentrations of the enzyme were assayed. The concentrations are stock solution concentration and diluted stock solution giving final concentration of $0.04 \mathrm{~g} / \mathrm{L}$. A capsule of chloramphenicol was added to the solution of enzyme to prevent any trace of microbial attack. Assay was carried according the method described by Bernfeld. ${ }^{27}$ Spectrophotometer readings were taken at a wave length of $540 \mathrm{~nm}$. The extinction coefficient was $\sim 181 \mathrm{~L} / \mathrm{mol} . \mathrm{cm}$. Kinetic parameters were determined by LWB plot, ${ }^{9}$ direct linear plot (DLP),${ }^{15}$ and alternative DLP (ADLP). ${ }^{13}$ Microsoft Excel was used to draw the lines linking the $\mathrm{x}$ any $\mathrm{y}$ points (observations) on the $\mathrm{x}$ and $\mathrm{y}$ axis respectively. In order to retain the lines drawn, the highest data point on the side representing the $y$-axis in table of variable (the points or observation) is left while the lower data points are deleted.

\section{Statistics}

Unpaired $t$-test for significant difference is carried out using internet based graph pad (www.graphpad. com/quick calcs /t-test). Micro-soft Excel was used to determine standard deviation $(n=6)$. The median values were adopted and standard deviation from median was according to Hozo et al. ${ }^{28}$

\section{Results and discussion}

To examine the conditions for various QSSAs multiple assays were carried out at different ranges of substrate concentration and different enzyme concentration, ranging from moderately large to large concentration. Kinetic parameters were generated by direct linear plot and double reciprocal plot, being the most widely used linear transformation of the MM equation. Both original direct linear plot (DLP) $)^{15}$ and modified DLP ${ }^{13}$ (otherwise called alternative DRP in this research) were used.

Following the assay of the enzyme $(0.04 \mathrm{~g} / \mathrm{L})$, with substrate concentration ranging from $2-4 \mathrm{~g} / \mathrm{L}$ direct linear plot carried out did not produce any intersection within the area of the graph sheet (Figure 1). The double reciprocal plot otherwise called Lineweaver Burk (LWB) plot (Figure 2) with the same substrate concentration range showed relative high coefficient of determination and as shown below Figure 2, yielded maximum velocity of hydrolysis, $v_{\max }(5.24 \pm 1.03$ $\mathrm{mM} / \mathrm{ml} . \mathrm{min})$ and $\mathrm{MM}, K_{\mathrm{m}}(35.94 \pm 8.26 \mathrm{~g} / \mathrm{L})$. The alternative direct linear plot (ADLP) (Figure 3) with substrate concentration stated earlier, yielded many intersections within the graphical space or area. The $v_{\text {max }}$ and $K_{\mathrm{m}}$ values shown under Figure 3, were $0.560 \pm 0.099$ $\mathrm{mM} / \mathrm{ml}$.min and $4.0 \pm 0.8 \mathrm{~g} / \mathrm{L}$ respectively.

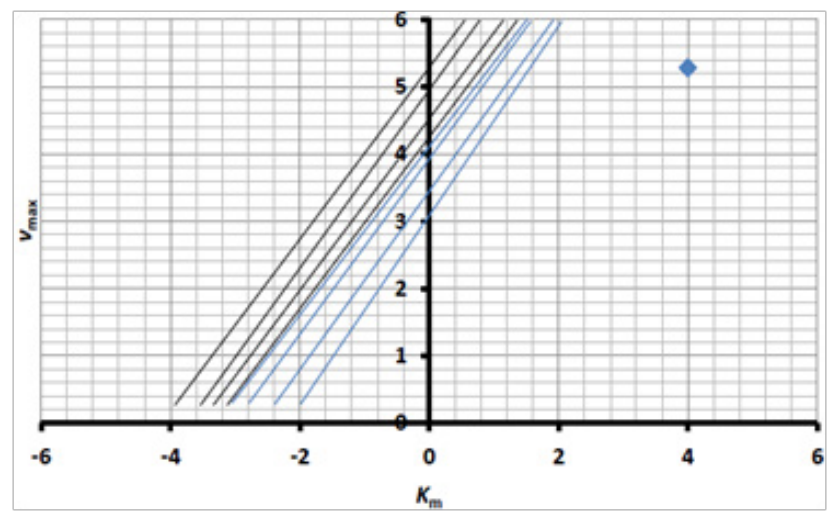

Figure I Direct linear plot ${ }^{15}$ of velocity of hydrolysis versus substrate concentration where the substrate concentration ranges from 2-4g/L. Absence of intersection does not allow any extrapolation.

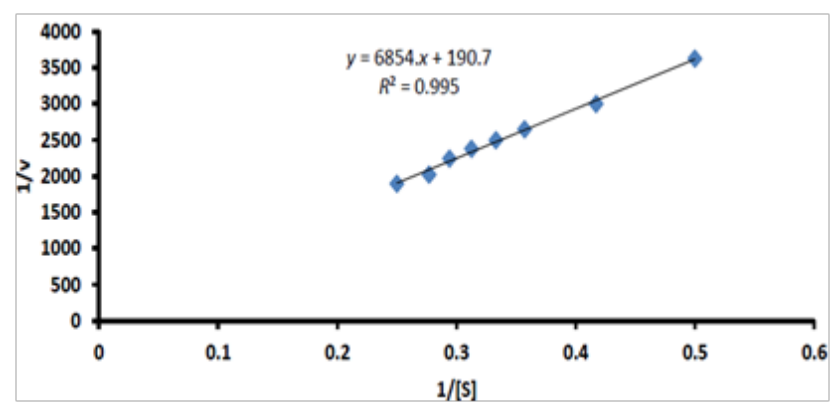

Figure 2 Line weaver Bulk plot where the substrate concentration ranges from $2-4 \mathrm{~g} / \mathrm{L}$

Line weaver Burk plot $(\mathrm{LWB})^{9}: v_{\max }=5.24 \pm 1.03 \mathrm{mM} / \mathrm{mL} \cdot \mathrm{min} ; \mathrm{K}_{\mathrm{m}}=35.94 \pm 8.26 \mathrm{~g} / \mathrm{L}$ (all data are median values, $n=6$ ).

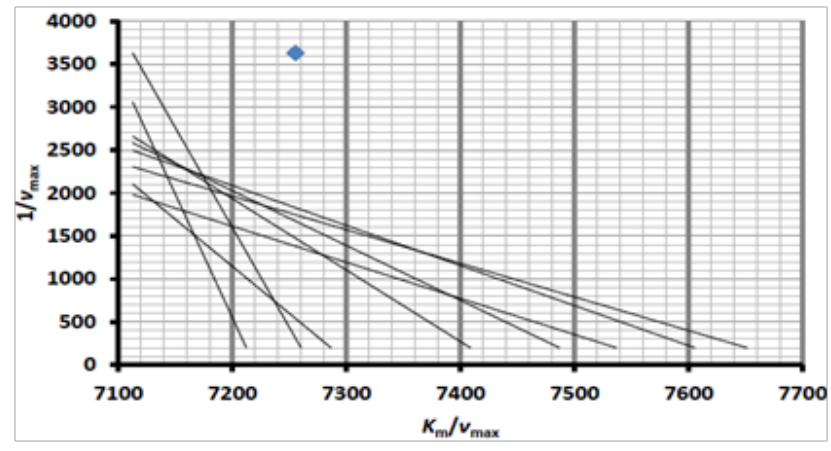

Figure 3 Alternative direct linear plot $(A D L T)^{13}$ where the substrate concentration ranges from 2-4 g/L.: $v_{\max }=0.560 \pm 0.099 \mathrm{mM} / \mathrm{mL} . \mathrm{min}$; $K_{\mathrm{m}} \approx 4.0 \pm 0.8 \mathrm{~g} / \mathrm{L}$ (all data are median values, $n=16$ ).

When the substrate concentration range is $10-20 \mathrm{~g} / \mathrm{L}$, the DLP (Figure 4) produced a greater number of nonintersecting lines than intersecting lines. Kinetic parameters, $v_{\max }(0.440 \mathrm{mM} / \mathrm{ml} . \mathrm{min})$ and $\mathrm{MM}, K_{\mathrm{m}}(2.0 \mathrm{~g} / \mathrm{L})$ were extrapolated and shown under Figure 4. Using to the same substrate concentration range, the LWB plot Figure 
5 yielded $v_{\max }(1.25 \pm 0.09 \mathrm{mM} / \mathrm{ml} . \mathrm{min})$ and $K_{\mathrm{m}}(29.20 \pm 2.83 \mathrm{~g} / \mathrm{L})$. The ADLP gave $v_{\max }(1.43 \pm 0.10 \mathrm{M} / \mathrm{ml} . \mathrm{min})$ and $\mathrm{MM}, K_{\mathrm{m}}(31.43 \pm 37.48$ $\mathrm{g} / \mathrm{L}$ ) as shown under Figure 6.

In three minutes duration of assay in which the substrate concentration range is $0.5-4 \mathrm{~g} / \mathrm{L}$ the DLP (Figure 7) gave $v_{\max }(0.62$ $\mathrm{mM} / \mathrm{ml} . \mathrm{min})$ and $K_{\mathrm{m}}(0.80 \mathrm{~g} / \mathrm{L})$, LWB plot (Figure 8) gave $v_{\text {max }}$ $(0.84 \pm 0.00 \mathrm{mM} / \mathrm{ml} . \mathrm{min})$ and $K_{\mathrm{m}}(1.86 \pm 0.07 \mathrm{~g} / \mathrm{L})$. The ADLP (Figure 9) gave $v_{\max }(1.0 \pm 0.3 \mathrm{mM} / \mathrm{ml} . \mathrm{min})$ and $K_{\mathrm{m}}(2.4 \pm 0.2 \mathrm{~g} / \mathrm{L})$.

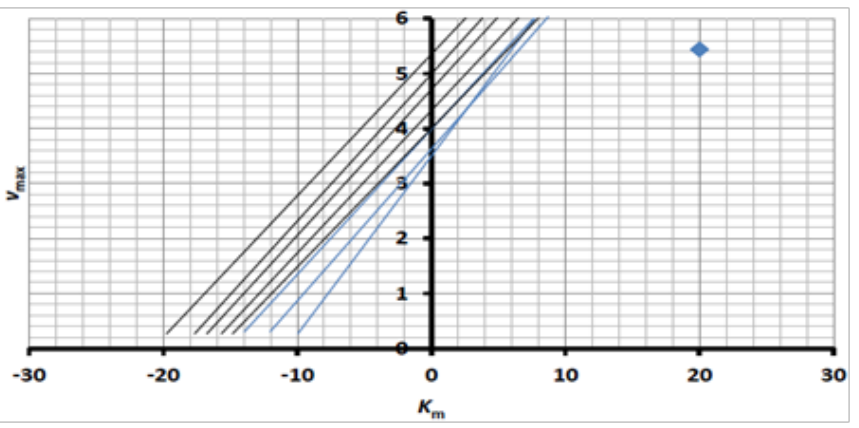

Figure 4 Direct linear plot of velocity of hydrolysis versus higher concentration substrate ranging from $10-20 \mathrm{~g} / \mathrm{L} . v_{\max }=0.440 \mathrm{mM} / \mathrm{mL} \cdot \mathrm{min} ; K_{\mathrm{m}}=2.0 \mathrm{~g} / \mathrm{L}$ (all data are median values)

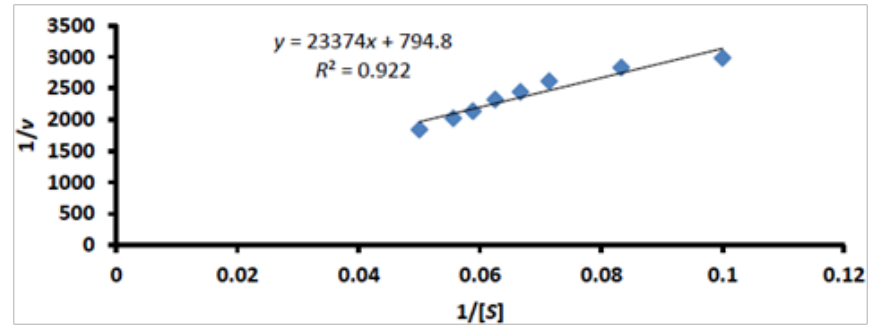

Figure 5 Line weaver Bulk plot where substrate concentration is high ranging from $10-20 \mathrm{~g} / \mathrm{L} . v_{\max }=1.25 \pm 0.09 \mathrm{mM} / \mathrm{mL} \cdot \mathrm{min} ; K_{\mathrm{m}}=29.30 \pm 2.83 \mathrm{~g} / \mathrm{L}$ (all data are median values, $n=6$ ).

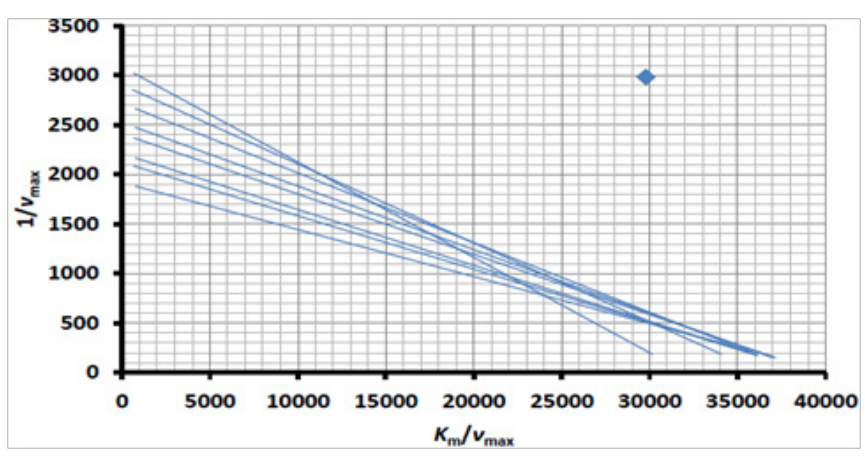

Figure 6 Alternative direct linear plot where the substrate concentration ranges from $10-20 \mathrm{~g} / \mathrm{L}$. $v_{\max }=1.43 \pm 0.10 \mathrm{mM} / \mathrm{mL} \cdot \mathrm{min} ; K_{\mathrm{m}} \approx 31.43 \pm 37.48 \mathrm{~g} / \mathrm{L}$ (all data are median values, $n=1 \mathrm{I}$ ).

The need to compare experimental velocity of hydrolysis of starch with theoretically determined velocity obtained by substituting measured substrate concentration, $K_{\mathrm{m}}$ and $v_{\max }$ obtained by extrapolation from LWB plot, DLP and ADLP into MM equation compelled $t$-test of significant difference between means. The results showed that, with substrate concentration range, $10-20 \mathrm{~g} / \mathrm{L}$, the velocities obtained from LWB plot, DLP, and ADLP were not statistically different $(P$
$>0.05$ ) from experimental values. The same scenario was observed with lower substrate concentration ranging from $2-4 \mathrm{~g} / \mathrm{L}$. However, since few lines formed common intersection point with DLP (Figure 1, Figure 4, and Figure 7) it is not scientifically and statistically advisable to assume reliable or definite kinetic parameters obtained from it. This may justify the assertion that the concentration regime used by researchers must obey MM formalism. ${ }^{15}$ This is to say that, hyperbolic relation must be observed between velocity and substrate concentration as to imply that every enzyme concentration has its substrate concentration that can achieve its saturation. This implies that there are different saturating concentrations of the substrate for different concentrations of the enzyme. If $[E]_{1}>[E]_{2}$ (where $[E]_{1}$ and $[E]_{2}$ are different concentrations of the enzyme), then $[S]_{\mathrm{sat}-1}>[S]_{\mathrm{sat}-}$ (where $[S]_{\text {sat- } 1}$ and $[S]_{\text {sat- } 2}$ are saturating concentrations for $[E]_{1}$ and $[E]_{2}$ respectively.). If so, contrary to what is accepted, the $K_{\mathrm{m}}$ values for the same enzyme under the same conditions cannot be the same for different concentrations of the enzyme otherwise the definition, substrate concentration $([S])$ at half maximum velocity of whatever enzymatic action may be invalid; this is obvious because different concentrations of enzyme have different $v_{\max }$. Unlike DPL, ADPL (Figure 3, Figure 6, and Figure 9) showed instances in which few lines showed common intersection and a lot more lines showed separate intersections which is a characteristic of non-error free data points. On account of this, nonparametric statistics was used to obtain the kinetic parameters with standard error determined as described elsewhere. ${ }^{28}$

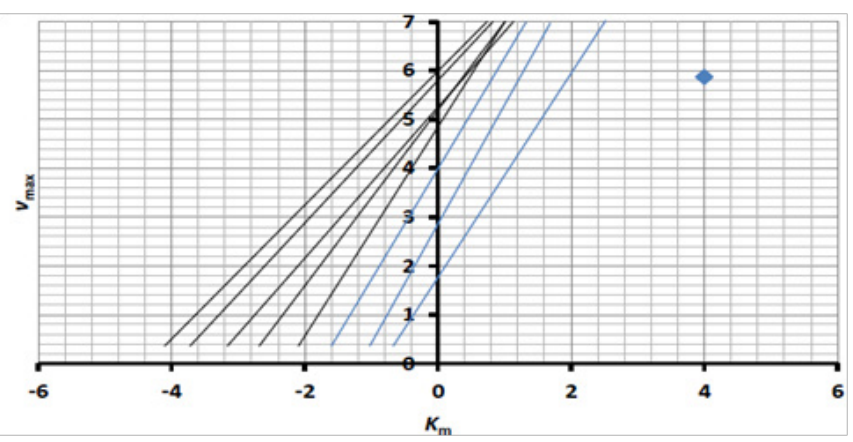

Figure 7 Direct linear plot where the substrate concentration ranges from $0.5-4 \mathrm{~g} / \mathrm{L}$ with high enzyme concentration and duration of assay is $3 \mathrm{~min} v_{\max }=$ $0.62 \mathrm{mM} / \mathrm{mL} \cdot \mathrm{min} ; K_{\mathrm{m}}=0.80 \mathrm{~g} / \mathrm{L}$ (all data are median values).

One very strange observation is that the kinetic parameters obtained from LWB using substrate concentration range, $2-4 \mathrm{~g} / \mathrm{L}$ were about 9-fold higher than the values from DLP (Figure 2 and Figure 3). Against the backdrop of the criticism against LWB ${ }^{10-12}$ it appears that the kinetic parameters from LWB are overestimates considering the fact that the substrate concentration regime is relatively low coupled with the fact that the concentration of the enzyme is relatively high. With the same enzyme concentration $(\approx$ $0.769 \mu \mathrm{mol} / \mathrm{L}$ ), but with higher substrate concentration range, $10-20$ $\mathrm{g} / \mathrm{L}$, the kinetic parameters from LWB and ADPL are not very widely different (Figure 5 and Figure 6). But the DLP (Figure 4) results suggest that MM formalism $v=\frac{\left[E_{\mathrm{T}}\right] k_{2}\left[S_{\mathrm{T}}\right]}{K_{\mathrm{m}}+\left[S_{\mathrm{T}}\right]}$ is not obeyed ${ }^{15}$ because of the occurrence of parallel lines thereby suggesting that on molar basis, as proposed in this study $\frac{\left[E_{\mathrm{T}}\right]}{\left[S_{\mathrm{T}}\right]} \gg 1^{29}$ if the molar mass $\left(M_{3}\right)$ of the substrate is $8.8 \exp (+7) \mathrm{g} / \mathrm{mol}^{24}$ It would appear therefore, that the 
kinetic parameters obtained from DLP with substrate concentration range, $2-4 \mathrm{~g} / \mathrm{L}$ is likely to be valid on the basis of Tzafriri's position ${ }^{19}$ on tQSSA and Schnell and Maini's position ${ }^{18}$ on rQSSA (Table 1). But the fact that the kinetic parameters from LWB plot appear to be validated at lower substrate concentration $(2-4 \mathrm{~g} / \mathrm{L})$ below the $K_{\mathrm{m}}$ seem to question the tenets of QSSA. However, all kinetic parameters are not valid on the basis of the condition for validity of RSA and SQSSA if in particular with respect to the latter, $\varphi=\left(1+\frac{k_{-1}}{k_{2}}\right)$ is $\gg 1$ But this requires experimental evidence for the value of $k_{-1}$. Therefore, the validity of kinetic parameters on the basis of sQSSA remains partially inconclusive for now. However, with respect to the kinetic parameters obtained from ADLP, the parameters seem to be clearly valid against the backdrop of the left hand side of Eq. (19b and 20b) being « 1 and with different scenario in respect of Eq. (17 and 22) for SQSSA and RSA respectively in which the condition for their validity was not fulfilled. This is coupled with the fact that $\left(1+\frac{k_{1}}{k_{2}}\right)$ may be $\geq 1$ with respect to Eq. (17), though this remains a fair speculation because gelatinized starch was the substrate with lower $K_{\mathrm{m}}$ compared to the raw starch i.e. affinity issue is relevant in this regard. ${ }^{25}$

Next is the validity and accuracy of kinetic parameters at moderately higher substrate concentration range $(10-20 \mathrm{~g} / \mathrm{L})$. Even at moderately high substrate concentration, the kinetic parameters from DLP (Figure 4), $K_{\mathrm{m}}$ in particular, were relatively low compared with the result achieved with LWB (Figure 5) and ADLP (Figure 6) both of which showed very close results. As stated earlier in the text, very few data point due to lack of multiple intersection expected of non-error free data and very few lines intersecting at common point within the graphical space may not allow for valid estimate of kinetic parameters. Despite this, the result obtained from DLP, LWB, and ADLP passes the test of validity on the basis of tQSSA and rQSSA (Table 1) but all accept the result from DLP, failed to pass the test of validity on the basis of SQSSA and RSA. The reason may be that the enzyme was yet to attain saturation going by the result of $\frac{\left[E_{\mathrm{T}}\right]}{\left[S_{\mathrm{T}}\right]} \gg 1^{29}$ being $\sim 3.38$ where the concentration of the substrate is $20 \mathrm{~g} / \mathrm{L}$ let alone $10 \mathrm{~g} / \mathrm{L}$ so long as $\mathrm{M}_{3}$ is $8.8 \exp (+7) \mathrm{g} / \mathrm{mol}$. It becomes imperative that the issue of units of variables be ascertained given the molar mass of the chemical species so as to clearly define the condition for validity.

Table I Validation of kinetic parameters on the basis of the condition of validity of various QSSA and RSA

\begin{tabular}{llll}
\hline \multicolumn{2}{l}{ With substrate concentration ranging from $\mathbf{2 - 4 g / L}$} & \\
\hline QSSA/RSA & LWB & ADLP & DLP \\
\hline $\operatorname{sQSSA}(17)$ & $\mathrm{L}=1.784 ; \mathrm{R}=\varphi 1.06$ & $\mathrm{~L}=11.28 ; \mathrm{R}=\varphi 1.5$ & - \\
$\operatorname{tQSSA}(19 \mathrm{~b})$ & $\varepsilon=\mu 0.03 \ll 1$ & $\varepsilon=\mu 0.054 \ll 1$ & - \\
$\mathrm{rQSSA}(20 \mathrm{~b})$ & $\mu 0.03 \ll 1$ & $\mu .6 \ll 1$ & - \\
$\mathrm{RSA}(22)$ & $1.78>1$ & $16.92 » 1$ & - \\
$K_{\mathrm{m}} / \mathrm{g} / \mathrm{L}$ & 35.94 & 4.00 & - \\
{$\left[S_{\mathrm{T}}\right]$ used } & 2.00 & 2.00 & -
\end{tabular}

With substrate concentration ranging from $10-20 \mathrm{~g} / \mathrm{L}$

\begin{tabular}{llll}
\hline QSSA/RSA & LWB & ADLP & DLP \\
\hline $\operatorname{sQSSA}(17)$ & $\mathrm{L}=1.72 ; \mathrm{R}=\varphi 1.34$ & $\mathrm{~L}=1.63 ; \mathrm{R}=\varphi 1.32$ & $\mathrm{~L}=5.64 ; \mathrm{R}=\varphi 6$ \\
$\operatorname{tQSSA}(19 \mathrm{~b})$ & $\varepsilon=\mu 043 \ll 1$ & $\varepsilon=\mu 0.43 \ll 1$ & $\varepsilon=\mu 0.12 \ll 1$ \\
$\operatorname{rQSSA}(20 \mathrm{~b})$ & $\mu 0.21 \ll 1$ & $\mu 0.46 \ll 1$ & $\mu 0.03 \ll 1$ \\
$\operatorname{RSA}(22)$ & $1.72>1$ & $1.75>1$ & $5.64 » 1$ \\
$K_{\mathrm{m}} / \mathrm{g} / \mathrm{L}$ & 29.3 & 31.43 & 2.00 \\
{$\left[S_{\mathrm{T}}\right]$ used } & 10 & 10 & 10
\end{tabular}

\begin{tabular}{|c|c|c|c|}
\hline \multicolumn{4}{|c|}{ With substrate concentration ranging from $0.5-4 \mathrm{~g} / \mathrm{L}$} \\
\hline QSSA/RSA & LWB & ADLP & DLP \\
\hline sQSSA(17) & $\mathrm{L}=71.71 ; \mathrm{R}=\varphi 1.27$ & $\mathrm{~L}=58.36 ; \mathrm{R}=\varphi 1.21$ & $\mathrm{~L}=130.18 ; \mathrm{R}=\varphi 1.63$ \\
\hline tQSSA(19b) & $\varepsilon=\mu 003 \ll 1$ & $\varepsilon=\mu 0.01 \ll 1$ & $\varepsilon \approx \mu 0.0051 \ll 1$ \\
\hline rQSSA(20b) & $\mu 0.01 \ll 1$ & $0.014 \ll 1$ & $\approx \mu 0.005 \ll 1$ \\
\hline $\operatorname{RSA}(22)$ & $71.71 » 1$ & $58.36 » 1$ & $717.08 » 1$ \\
\hline$K_{\mathrm{m}} / \mathrm{g} / \mathrm{L}$ & 1.86 & 2.4 & 0.80 \\
\hline$\left[\mathrm{S}_{\mathrm{T}}\right] / \mathrm{g} / \mathrm{L}$ & 0.50 & 0.50 & 0.50 \\
\hline
\end{tabular}

$\varphi=\left(1+\frac{k_{-1}}{k_{2}}\right) ; \mu=\frac{k_{2}}{k_{-1}+k_{2}} ; \mathrm{L}$ and $\mathrm{R}$ are left hand side and right hand side of the inequality. The numbers in parenthesis are equation numbers in the text, 
theoretical section to be specific.

Next in line is the result from the assay of a very high concentration of the enzyme, $\sim 1.92 \mu \mathrm{mol} / \mathrm{L}$ with much lower concentration of the substrate ranging from $0.5-4.0 \mathrm{~g} / \mathrm{L}$. Unlike the high values of kinetic parameters resulting from LWB plot following assay of $0.04 \mathrm{~g} / \mathrm{L}(\sim 0.769 \mu \mathrm{mol} / \mathrm{L})$, the results from the assay of $\sim 1.92 \mu \mathrm{mol} / \mathrm{L}$ with low substrate concentration ranging from $0.5-4 \mathrm{~g} / \mathrm{L}$ (Figure 8 ) showed lower values of kinetic parameters which were very close to the result obtained from ADLP (Figure 9). Ultimately, all kinetic parameters were valid having satisfied the condition for validity of rQSSA and tQSSA but totally invalid on the basis of the condition for validity of RSA and SQSSA (Table 1) for reasons stated earlier in the text. However, Tzafriri's ${ }^{19}$ position on the condition for validity of tQSSA seems to validate every kinetic parameter regardless of the concentration regime of the substrate or the enzyme employed. It seems therefore, that it cannot be used to ascertain whether or not the substrate concentration employed is $<$ the saturating concentration. The substrate concentration must be far less than the saturating concentration such that $\frac{\left[E_{\mathrm{T}}\right]}{\left[S_{\mathrm{T}}\right]} \gg 1$ may hold to justify the condition of tQSSA but Tzafriri approach cannot differentiate between $\frac{\left[E_{\mathrm{T}}\right]}{\left[S_{\mathrm{T}}\right]} \gg 1$ and $\frac{\left[E_{\mathrm{T}}\right]}{\left[S_{\mathrm{T}}\right]} \ll 1$ since kinetic parameters obtained under both conditions are validated (Table 1). Only condition for validity of rQSSA can ascertain if $\frac{\left[E_{\mathrm{T}}\right]}{\left[S_{\mathrm{T}}\right]} \gg 1$ or $\frac{\left[E_{\mathrm{T}}\right]}{\left[S_{\mathrm{T}}\right]} \ll 1$ and thus verify if the assay was at very high enzyme concentration. By so doing however, when there is an excess of enzyme $E$, the condition for validity of SQSSA (and RSA) ${ }^{(17,23)}$ as originally cited by Schnell et al..$^{29}$ cannot hold. Substrate depletion is characteristic of the condition $\frac{\left[E_{\mathrm{T}}\right]}{\left[S_{\mathrm{T}}\right]} \gg 1$ and therefore, instead of enzyme substrate complex, $C$ being in a QSS with respect to $S$, at high enzyme concentration Schnell et al. ${ }^{29}$ proposed that the substrate, $S$ is in QSS with respect to $C\left(\frac{\mathrm{d} S}{\mathrm{~d} t} \approx 0\right)$. It means too that velocity expression should be a departure from MM equation such that,

$$
v=\frac{d[p]}{d t}=\frac{v_{\max }\left[S_{T}\right]}{\left[K_{s}\right]+\left[S_{T}\right]}
$$

Where $K_{s}=k_{-1} / k_{1}$; this may be seen to be $<\frac{k_{-1}+k_{2}}{k_{1}} 1$. This is reasonable because at high enzyme concentration but with very low substrate concentration, the enzyme cannot attain saturation. However, one should not hesitate to state that the mere fact that $K_{\mathrm{m}}$ is lower than expected does not necessarily suggest that $K_{\mathrm{s}}$ should have been the case because the magnitude of $K_{\mathrm{m}}$ sometimes expresses the affinity of the enzyme for the substrate. In this case the reverse rate constant $\mathrm{k}_{-1}$ at high affinity should be very low and consequently, $\left(1+\frac{k_{1}}{k_{2}}\right)$ should $\rightarrow 1$. What is important is that $\frac{\left[E_{\mathrm{T}(\mathrm{mol})}\right]}{\left[S_{\mathrm{T}(\mathrm{mol})}\right]} \leq 1$.

Incidentally, there is an opinion that "high affinity of an enzyme for a substrate may lead to binding of a significant proportion of substrate to the enzyme" with the implication, according to ${ }^{29}$ and references therein, that $\mathrm{MM}$ equation and its double reciprocal plot become, increasingly invalid. Going by this assertion, all kinetic data from DLP, ADLP, and non-linear regression analysis should also be invalid. It appears that substrate unbinding ${ }^{30}$ which is a reflection of unstable or weak affinity may therefore, enhance the validity of the kinetic parameters. Thus kinetic parameters from assay of enzymes using raw starch to which the enzyme has much lower affinity ${ }^{25}$ and in which consequently, $k_{1}$ may be high, may be considered to be valid going by the position held by Reuveni et al..$^{30}$ and Schnell et al. ${ }^{29}$

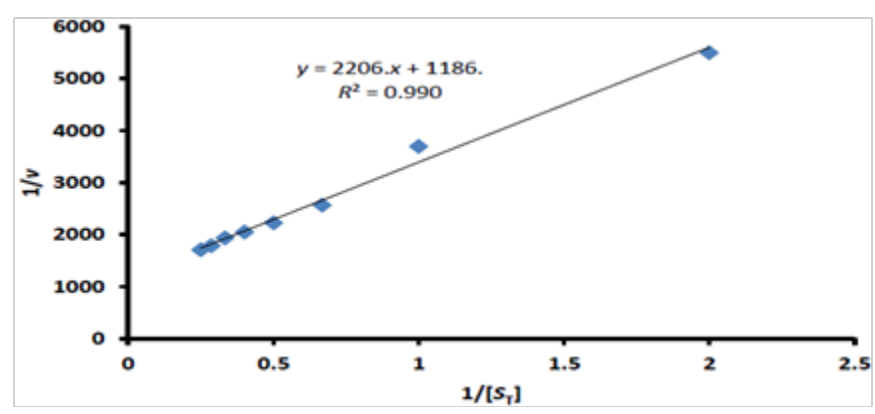

Figure 8 Line weaver Burk plot where substrate concentration ranges from $0.5-4 \mathrm{~g} / \mathrm{L}$ with high enzyme concentration and duration of assay equal to $3 \mathrm{~min}$ $v_{\text {max }}=0.84 \pm 0.00 \mathrm{mM} / \mathrm{mL} . \mathrm{min} ; K_{\mathrm{m}}=1.86 \pm 0.07 \mathrm{~g} / \mathrm{L}$ (all data are median values).

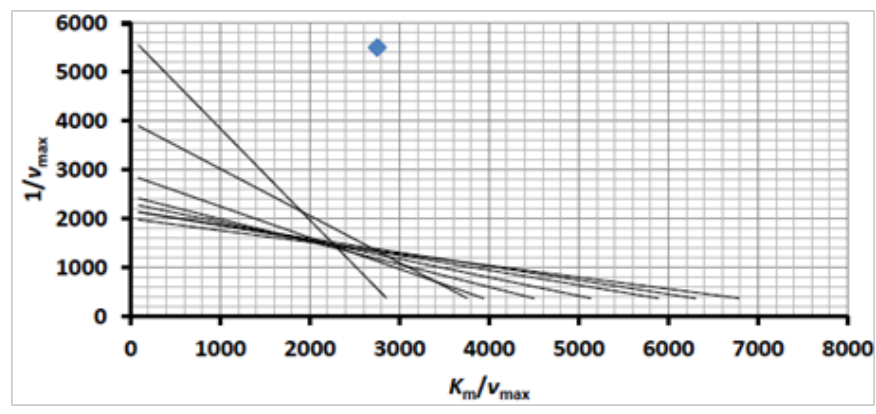

Figure 9 Alternative direct linear plot where substrate concentration ranges from $0.5-4 \mathrm{~g} / \mathrm{L}$ with high enzyme concentration and duration of assay is $3 \mathrm{~min}$ : $v_{\text {max }}=1.0 \pm 0.3 \mathrm{mM} / \mathrm{mL} \cdot \min ; K_{\mathrm{m}}=2.4 \pm 0.2 \mathrm{~g} / \mathrm{L}$ (all data are median values, $n=\mathrm{II}$ ).

But this disposition toward lower affinity as one that promotes higher velocity of enzymatic action is mildly speaking, very strange. What may be important for the purpose of validity is that various QSSA must be put into consideration before the determination of valid kinetic parameters as may be predetermined by the concentration of the enzyme in particular given substrate concentration range intended either for in vitro experiment or in vivo trial experiment for therapeutic application. Since in vitro experiments are intended to give preliminary insight into what in vivo experimental outcome might be, it is very important to consider all QSSA. Nonetheless, lower concentration of $E$ is often the case in most in vitro experiment and so, the substrate concentration regime should be chosen such that $\frac{\left[S_{\mathrm{T}}\right]}{\left[E_{\mathrm{T}}\right]} \gg 100^{31-33}$ so as to satisfy the condition for validity of not only SQSSA but what Schnell ${ }^{7}$ referred to as reactant stationary assumption.

On the other hand, it has been reported that the intra cellular or in vivo concentration of a chosen enzyme is usually » (or just $>$ ) the extra cellular or in vitro concentration for assay or such in vivo concentration of the enzyme may just be of the same magnitude as their substrate ${ }^{18,29}$ and, consequently, a significant fraction of the substrate $S$ can be bound as enzyme-substrate complex, $C$. It seems that when the concentration of $S$ is relatively close to the concentration 
of $E$, LWB plot (Figure 2) overestimates the kinetic parameters unlike ADLP(Figure 3). Yet, despite the suggestion that sQSSA breaks down in vivo due to higher enzyme concentration, there seems to be a contradictory suggestion that, the advantage of QSSA is that "it reduces the dimensionality of the system, passing from two equation (full system) to one (MM approximation or sQSSA) and speeds up numerical simulations greatly, especially for large networks as found in vivo". ${ }^{34}$ In this research however, it has been shown that the kinetic parameters can be valid under condition that satisfy rQSSA because the concentration regimes of the enzyme employed $(0.76$ and $1.92 \mu \mathrm{mol} / \mathrm{L}$ ) seem to be respectively higher and much higher than the concentration of $S(2-4 \mathrm{~g} / \mathrm{L} ; 0.5-4 \mathrm{~g} / \mathrm{L}$ and $10-20 \mathrm{~g} / \mathrm{L})$ (Table 1). This, perhaps, should be applicable to in vivo condition.

It must be pointed out that it is the experimentally generated velocities of hydrolysis as applicable to hydrolases for instance, that determines whatever the kinetic parameters generated by different means, DLP, ADLP and non-linear plot, given a range of substrate concentration and not the converse. The velocities generated may be marred by error in pipetting, inconsistence timing (duration less than the chosen duration) etc. With regard to the ADLP and DLP chosen in this research, the issue of precision is imperative and thus demands conditions for the precise if not valid estimates of kinetic parameters. It has been posited that "the point of intersection of two lines is most precisely defined if they intersect at right angles, and least precisely if they intersect at a very acute angle"; this can best be achieved if the range of $S$ and $v$ is as great as possible which requires that MM equation must be obeyed. There is also, the requirement that $v$ must be evenly spaced. ${ }^{15}$ However, $v$ is very much outside the control of the experimenter because, as long as $\frac{\left[S_{\mathrm{T}}\right]}{\left[E_{\mathrm{T}}\right]} \gg 1$, the relationship, $\frac{\Delta\left[P_{\mathrm{mc}}\right]}{\Delta[S]}$ may not be consistently constant as $S$ approaches saturating concentration. Thus unlike this research (the result is in Table 1) where it seems the condition for validity of rQSSA is totally the case, the position of Eisenthal et $\mathrm{a}^{15}$ is that of sQSSA in which DLP may be practicable. It is obvious therefore, that allowing $\frac{\Delta\left[P_{\mathrm{mc}}\right]}{\Delta\left[S_{\mathrm{mc}}\right]}$ being constant or nearly so, over the substrate concentration range used violets MM condition or condition for validity of SQSSA. This violation is very much applicable to the results from this research considering (Figure 1) (Figure 4). It could be noticed in this research that where the concentration $(2-4 \mathrm{~g} / \mathrm{L})$ of the substrate, $S$ is not widely different from the concentration of $E$, the kinetic parameters from LWB plot is widely different from the result from ADLP (Figure 2)

(Figure 3). It seems within that substrate concentration range $\frac{\Delta\left[P_{\mathrm{mc}}\right]}{\Delta\left[S_{\mathrm{mc}}\right]}$ was constant or nearly so over a substantial number of different substrate concentrations. This is clearly against the MM condition. But with 5-fold increase in the concentration of the substrate at the same concentration of the enzyme, the kinetic parameters from ADLP and LWB plot are very close. But this is not to say that the result from LWB plot is becoming accurate because every linear relationship must yield a constant gradient with a very data point which is impossible with tendency towards hyperbolic relationship between $v$ and $S$. Thus as long as the concentration of $E$ is higher than every concentration range of $S$ (Figure 8) (Figure 9) in particular) on mole to mole basis, the condition for validity of rQSSA appears to be obeyed. One must not overlook emerging scenario in which with higher concentration of the substrate at fixed concentration of the enzyme (Figure 5 and Figure 6) and when the concentration of $E$ seems to be » the concentration of $S$ (Figure 8 and Figure 9), the kinetic parameters from LWB plot and ADLP seem to be closer. It appears therefore, that there is a lower concentration limit below which the kinetic parameters obtainable from LWB plot becomes widely different from those of ADLP.

Another issue that needs to be examined in the light of this research is the claim that the kinetic constants such as $K_{\mathrm{m}}$ are identical in vivo and in vitro. This is only possible if in vitro conditions, $\mathrm{pH}$ temperature and even ionic strength allows the similarity of result derivable from the assay of the enzyme even though the concentration of the latter is always higher in vivo than in vitro. Otherwise the substrate concentration regime needed to achieve maximum velocity for the same enzyme with concentration, $\left[E_{1}\right]$ may not be the same as the concentration regime needed to achieve maximum velocity for the same enzyme with concentration, $\left[E_{2}\right]$ if $\left[E_{1}\right]$ is $>\left[E_{2}\right]$. Substrate concentration at half maximum velocity of hydrolysis with $E_{1}$ is not equal to substrate concentration at half maximum velocity of hydrolysis with $E_{2}$. Thus it is doubtful whether the $K_{\mathrm{m}}$ of $E=K_{\mathrm{m}}$ of $E_{2}$. This is partially exemplified when the same concentrations of $E$ were assayed at different substrate concentration ranges (Figure 2, Figure 3 and Figure 6) considering LWB plot and ADLP only and when much higher concentration of $E$ was assayed with much lower substrate concentration range (Figure 8 and Figure 9). This scenario is expected to be the case when kinetic result from in vivo assay of the same enzyme is compared with result from in vitro study given the same condition but with much lower in vitro concentration of the enzyme.

It is very necessary to state that the symbol $K_{\mathrm{m}}$ which appears in Table 1 may not represent what it normally represents, the substrate concentration at half maximum velocity of hydrolysis of the substrate by the enzyme as long as the kinetic parameters are not generated under the condition that satisfies sQSSA. Consequently, $K_{\mathrm{s}}$ should be the appropriate symbol which stands for a different parameter, the equilibrium dissociation constant of $C$ (or $E S$ ) which is appropriate for situation in which $\frac{\left[E_{\mathrm{T}}\right]}{\left[S_{\mathrm{T}}\right]} \gg 1$. Thus it is even more appropriate to use a general symbol, $K_{\mathrm{ms}}$ such that substitution of its experimentally generated value, using LWB plot, DLP, and ADLP and even nonlinear plot into various validation equations may determine whether or not the kinetic parameter satisfies the condition of validity of any of the QSSA or RSA. Thus if it satisfies the condition for validity of sQSSA, then $K_{\mathrm{ms}}$ should be $K_{\mathrm{m}}$. Of course if $K_{\mathrm{ms}}$ is certified to be $K_{\mathrm{m}}$, the kinetic parameter, $v_{\text {max }}$ becomes valid. Thus what may be called $v_{\max }$ when $K_{\mathrm{ms}}$ is $K_{\mathrm{s}}$, is not truly the case because it is not achieved when the enzyme has been saturated which is only possible when $\frac{\left[S_{\mathrm{T}}\right]}{\left[E_{\mathrm{T}}\right]} \gg 1$, a condition that is in line with the requirement of sQSSA.

\section{Conclusion}

In conclusion, kinetic parameters which should have been $K_{\mathrm{m}}$ and $v_{\max }$, were determined by subjecting the experimental data, velocity of hydrolysis of substrate to DLP, LWB plot, and ADLP with different substrate concentration regime; the plots did not give similar results. Assay of the enzyme at its fixed concentration with different substrate concentration ranges gave different kinetic parameters. On mass-mass basis unlike mole-mole basis, one may falsely validate the kinetic 
parameters due to misapplied QSSA. Since the concentration of $E$ is generally higher than the concentration of $S$, the kinetic parameters generated were seen to be valid on the basis of the condition for validity of rQSSA; in this case $K \mathrm{~s}$ instead of $K_{\mathrm{m}}$ was generated and consequently, the $v_{\max }$ is not truly what it should be because the enzyme was not saturated with the substrate.

\section{Acknowledgement}

None

\section{Conflict of interest}

There is no conflict of interest of any kind.

\section{References}

1. Grima R, Walter NG, Schnell S. Single-molecule enzymology à la Michaelis -Menten. FEBS J. 2014;281(2):518-530.

2. Ueda $\mathrm{S}$, Oda $\mathrm{M}$, Imamura $\mathrm{S}$, et al. Transient-phase kinetic studies on the nucleotide binding to 3alpha-hydroxysteroid dehydrogenase from Pseudomonas sp. B-0831 using fluorescence stopped-flow procedures. Eur J Biochem. 2004;271(19):1774-1780.

3. Miao J, Fan Y, Li J, et al. Kinetics of medium-temperature $\alpha$-amylase hydrolyzed Huai yam powder. Agric Sci. 2013;4(9B):5-11.

4. Al-Qodah Z, Dghstani H, Geopel Ph, et al. Determination of kinetic parameters of alpha-amylase producing thermophilic Bacillus sphaericus. Afri J Biotechnol. 2007;6(6):699-706.

5. Hefnawy ME, Sakran M, Ismail AI, et al. Extraction, purification, kinetic and thermodynamic properties of urease from germinating Pisum Sativum L seeds. BMC Biochem. 2014;15(15):1-820.

6. Riaz M, Perveen R, Javed MR, et al. Kinetic and thermodynamic properties of novel glucoamylase from Humicola sp. Enzyme Microb. Techno. 2007;41(5):558-564.

7. Schnell S. Validity of the Michaelis - Menten equation - steady state or reactant stationary assumption: that is the question. FEBS $J$. 2014;281(2):464-472.

8. Michaelis L, Menten ML. The kinetics of invertin action. FEBS Lett. 2013;587(17):2712-2720.

9. Lineweaver H, Burk D. The determination of enzyme dissociation constants. J Am Chem Soc. 1934;56(3):658-666.

10. Wilkinson GN. Statistical Estimations in Enzyme Kinetics. Biochem J. 1961;80:324-332.

11. Jeričević Ž, Kušter Ž. Non-linear optimization of parameters in Michaelis-Menten kinetics. Croatica Chemica Acta. 2005;78(4):519523.

12. Baici A. Enzyme kinetics: the velocity of reactions. Biochem J. 2006;1-3.

13. Baici A, Novinec M, Lenarčič B. Kinetics of the Interaction of Peptidases with Substrates and Modifiers. Proteases: Structure and Function. 2013; p. 37-84.

14. Cornish - Bowden A, Eisenthal R. Statistical considerations in the estimation of enzyme kinetic parameters by the direct linear plot and other methods. Biochem J. 1974;139(3):721-730.
15. Eisenthal R, Cornish-Bowen A. The direct linear plot: A new graphical procedure for estimating enzyme kinetic parameters. Biochem $J .1974 ; 139(3): 715-720$.

16. Briggs GE, Haldane JB. A note on the kinetics of enzyme action. Biochem J. 1925;19(2):338-339.

17. Segal LA, Slemrod M. The quasi-steady -state assumption: a case study in perturbation. SIAM Rev. 1989;31(3):446-477.

18. Schnell S, Maini PK. Enzyme kinetics at high enzyme concentration. Bull Math Biol. 2000;62(3):483-499.

19. Tzafriri AR. Michaelis-Menten kinetics at high enzyme concentrations. Bull Math Biol. 2003;65(6):1111-1129.

20. Udema II. Substrate Mass Conservation in Enzyme Catalyzed Amylolytic Activity. Int J Biochem Res Rev. 2017;18(1):1 -10.

21. Van Slyke DD, Cullen GE. The mode of action of urease and of enzymes in general. J Biol Chem. 1914;19(2):141-180.

22. Borghans JA, De Boer RA, Segel LA. Extending the quasi-steady state approximation by changing variables. Bull Math Biol. 1996;58(1):4363.

23. Segel LA. On the validity of the steady state assumption of enzyme kinetics. Bull Math Biol. 1988;50(6):579-593.

24. Van Soest JJG, Benes K, de Wit D, et al. The influence of starch molecular mass on the properties of extruded thermoplastic starch. Polymer. 1996;37(16):3543-3552.

25. Ruiz MI, Sanchez CI, Torrres RG, et al. Enymatic hydrolysis of cassava starch for production of bioethanol with a Colombian wild yeast strain. J Braz Chem Soc. 2011;22(12):2337-2343.

26. Cornish Bowden A. The use of the direct linear plot for determining initial velocities. Biochem J. 1975;149(2):305-312.

27. Bernfeld P. Amylases, alpha and beta. Methods Enzymol. 1995;1:149158.

28. Hozo SP, Djulbegovic B, Hozo I. Estimating the means and variance from the median range and the size of a sample. BMC Med Res Methodol. 2005;5(13):1-10.

29. Schnell S, Maini PK. A Century of Enzyme Kinetics: Reliability of the $\mathrm{Km}$ and $\mathrm{v}_{\max }$ estimates. Comments on Theor Biol. 2003;8(2):169-187.

30. Reuveni S, Urbakh M, Klafter J. Role of substrate unbinding in Michaelis-Menten enzymatic reactions. Proc Natl Acad Sci USA. 2014;111(12):4391-4396.

31. Stayton MM, Fromm HJ. A computer analysis of the validity of the integrated Michaelis - Menten equation. J Theor Biol. 1979;78(3):309323.

32. Wong JTF. On the steady - state method of enzyme kinetics. J Am Chem Soc. $1965 ; 87(8): 1788-1793$

33. Heineken FG, Tsuchiya HM, Aris A. On the mathematical status of the pseudo - steady state hypothesis of biochemical kinetics. Math Biosci. 1967;1(1):95-113.

34. Pedersen MG, Bersani AM, Bersani E, et al. The total quasi-steady-state approximation for complex enzyme reactions. Mat Comput Simulat. 2018;79(4):1010-1019. 